\title{
Zeranol Down-Regulates p53 Expression in Primary Cultured Human Breast Cancer Epithelial Cells through Epigenetic Modification
}

\author{
Weiping Ye ${ }^{1}$, Pingping Xu ${ }^{1}$, Robert Jen ${ }^{1}$, Eric Feng ${ }^{1}$, Saiyi Zhong ${ }^{1}$, Hong Li ${ }^{1}$, Shu-Hong Lin ${ }^{1}$, \\ Jie-Yu Liu ${ }^{1}$ and Young C. Lin ${ }^{1,2}$,* \\ 1 Laboratory of Reproductive and Molecular Endocrinology, College of Veterinary Medicine, The \\ Ohio State University, Columbus, OH 43210, USA; E-Mails: ye.44@ osu.edu (W.Y.); \\ xu.200@osu.edu (P.X.); jenrt@mail.uc.edu (R.J.); fanx40@gmail.com (E.F.); zhong.66@osu.edu \\ (S.Z.); li.801@osu.edu (H.L.); lin.833@ osu.edu (S.-H.L.); liu.1048@osu.edu (J.-Y.L.) \\ 2333 Goss Laboratory, 1925 Coffey Road, The Ohio State University Comprehensive Cancer Center, \\ Columbus, OH 43210, USA
}

* Author to whom correspondence should be addressed; E-Mail: lin.15@ osu.edu; Tel.: +1-614-292-9607; Fax: +1-614-292-6473.

Received: 25 January 2011; in revised from: 30 January 2011 / Accepted: 12 February 2011 / Published: 25 February 2011

\begin{abstract}
Epidemiological studies have suggested that there are many risk factors associated with breast cancer. Silencing tumor suppressor genes through epigenetic alterations play critical roles in breast cancer initiation, promotion and progression. As a growth promoter, Zeranol $(Z)$ has been approved by the FDA and is widely used to enhance the growth of beef cattle in the United States. However, the safety of $Z$ use as a growth promoter is still under debate. In order to provide more evidence to clarify this critical health issue, the current study investigated the effect of $\mathrm{Z}$ on the proliferation of primary cultured human normal and cancerous breast epithelial cells (PCHNBECs and PCHBCECs, respectively) isolated from the same patient using MTS assay, RT-PCR and Western blot analysis. We also conducted an investigation regarding the mechanisms that might be involved. Our results show that $\mathrm{Z}$ is more potent to stimulate PCHBCEC growth than PCHNBEC growth. The stimulatory effects of $Z$ on PCHBCECs and PCHBCECs may be mediated by its down-regulating expression of the tumor suppressor gene p53 at the mRNA and protein levels. Further investigation showed that the expression of DNA methylatransferase $1 \mathrm{mRNA}$ and protein levels is up-regulated by treatment with $\mathrm{Z}$ in
\end{abstract}


PCHBCECs as compared to PCHNBECs, which suggests a role of $\mathrm{Z}$ in epigenetic modification involved in the regulation of p53 gene expression in PCHBCECs. Our experimental results imply the potentially adverse health effect of $\mathrm{Z}$ in breast cancer development. Further study is continuing in our laboratory.

Keywords: breast cancer; growth promoter; zeranol; p53; DNMT1

\section{Introduction}

Breast cancer remains a serious problem in the U.S. It is estimated that more than one-fourth of cancer patients were breast cancer patients in 2010 and it ranks as the second leading cause of cancer-related deaths [1]. The risk factors associated with breast cancer have been well studied. Epidemiological studies suggest that there are many risk factors, such as dietary fat and environmental estrogenic endocrine disruptors. It has been reported that breast cancer cells express high levels of aromatase, which can convert androgens into estrogens, resulting in high concentrations of estrone $\left(E_{1}\right)$ and estradiol $\left(E_{2}\right)$ in breast tissue [2,3]. This finding might be the major reason for high risk of breast cancer in postmenopausal women and obese women.

Zearalenone, a stable natural product that mimics estrogen activity, is carcinogenic and hazardous to human health [4]. It was reported that zearalenone may represent a growth promoter in exposed patients and there is a possible relationship between environmental mycoestrogen exposure and the development of central precocious puberty [5]. Zeranol (Z), produced from zearalenone, is a non-estrogenic anabolic growth promoter and is widely used in the U.S. beef industry to accelerate weight gain, improve feed conversion efficacy, and increase the lean meat-to-fat ratio [6]. It is approved by the FDA based on its toxicity information. However, the potentially adverse health concerns associated with $\mathrm{Z}$ have caused the European Union (EU) to refuse the import of beef products with any growth promoter implantation from the U.S., resulting in a serious legal issue between the U.S. and the EU. We need greater concrete evidence to clarify this important health issue in order to bring awareness to the FDA.

Both zearalenone and $\mathrm{Z}$ can bind to the active site of human estrogen receptor $\alpha(\mathrm{ER} \alpha)$ and ER $\beta$ in a manner similar to $17 \beta$-estradiol [7]. As a food contaminant, the intake of $\mathrm{Z}$ is very hard to avoid [8]. It is still not clear whether $Z$ and its metabolites cause any adverse health risks from consuming beef products produced from $Z$-implanted beef cattle. Researchers have found that low concentrations of $Z$ can increase ER $\alpha$-positive human breast cell growth, but a high concentration of $Z$ can reduce growth of both ER $\alpha$-positive and ER-negative cell lines [9]. Our previous data showed that $\mathrm{Z}$ was able to transform normal human breast epithelial cells and increase human breast cell growth in a dose-dependent manner [10]. Z can also down-regulate the estrogen-regulated human breast cancer candidate suppressor gene, protein tyrosine phosphatase $\gamma$ (PTP $\gamma)$ expression [7]. Our laboratory's recent experimental results showed that pre-adipocytes isolated from the cattle 60 days post Z-implantation ( $72 \mathrm{mg} /$ pellets/animal) grow about 12-times faster than the pre-adipocytes isolated from control cattle [11]. Treatment with $0.2,1$ and $5 \% \mathrm{Z}$ sera (ZS) harvested from the cattle 30 days post implantation in culture medium significantly stimulated MCF-10A and MCF-7 cell growth [12,13]. We 
also have evidence showing that leptin, which plays a role in breast cancer development in obesity, induces human breast cancer epithelial cell sensitivity to Z [14].

The relationship between the consumption of beef products with residue of $\mathrm{Z}$ and its metabolites and cancer development is still in debate. However, epidemiology studies showed that the semen quality of fertile U.S. males is related to their mother' beef consumption during their pregnancy [15]. It has been reported that higher red meat intake in adolescence may increase the risk of premenopausal breast cancer [16]. Early in 1989, Aw and colleagues reported that workers were exposed to Z formulate pellets along with a package of animal growth promoter containing $\mathrm{Z}$ as its active ingredient in a small manufacturing plant. Their industrial exposure to $\mathrm{Z}$ caused one child to be afflicted with advanced bone aging due to his parents wearing their work clothes home (estimated $32 \mathrm{mg}$ of $\mathrm{Z}$ on contaminated work clothes) [17]. It is well-known that the tumor suppressor gene p53 plays an important role in controlling cell life and death [18]. Loss of normal p53 function occurs in all types of human tumors, including breast cancer [19-21]. Baker and co-worker determined the p53 mutation status in 246 women with primary breast cancer and identified the p53 mutations in $26 \%$ of patients that may also be associated with poor prognosis [22]. It is estimated that at least one-third of non-familial breast cancer patients bear mutations in p53 [23]. Additionally, mutation of p53 is correlated with heritable mutations in BRCA1 [24]. The mechanisms of regulating p53 expression in breast cancer cells have been well studied. Our previous investigation found that the pre-adipocytes derived from the heifer after two month of Z-implantation grew about 12-times faster than those from the control heifer. The expression of p53 mRNA and protein was also lower in the $\mathrm{Z}$ treated group than the control [11]. However, the function of growth promoter- $Z$ on regulation of p53 in primary cultured human normal and cancerous breast epithelial cells is still unknown.

Epigenetics is the study of nuclear inheritance that is not based on differences in DNA sequences, but the changes in DNA structure partially due to altered DNA methylation. DNA methyltransferase 1 (DNMT1) is known to be a major DNA methyltransferase that can catalyze a methyl group in cytosine residues within $\mathrm{CpG}$ dinucleotides and lead to the tumor suppressor gene silencing [25-27]. CpG methylation in the p53 promoter region was detected in breast cancer [28]. Our investigation has centered around determining whether $\mathrm{Z}$ stimulates breast cancer cell lines as well as primary cultured human normal and cancerous breast epithelial cells mediated by regulating DNA methyltransferase 1 (DNMT1) and hypermethylation in the promoter regions, thus resulting in the silencing of the tumor suppressor gene, p53 expression. The current study investigates the effect of $\mathrm{Z}$ on the growth of primary cultured human normal and cancerous breast epithelial cells as well as the underlying mechanisms. Our results indicate that $\mathrm{Z}$ is more potent to stimulate primary culture human breast cancer epithelial cells (PCHBCECS) growth than primary culture human normal breast epithelial cells (PCHNBECS) and the stimulatory effects may be mediated by regulating the expression of DNMT1 and down-regulating p53 expression in PCHBCECs but not in PCHNBECs.

\section{Results and Discussion}

\subsection{Z Increases the Proliferation of PCHNBECs and PCHBCECs}

Our previous experimental results showed that $\mathrm{Z}$ stimulates MCF-7 cell and MCF-10A cell growth [10]. The serum harvested from the heifer one month post $\mathrm{Z}$ implantation is more potent in 
stimulating human breast cancer cell lines as well as PCHBCEC growth than that from control heifers. In the current study, we evaluated the effects of Z on PCHNBEC's and PCHBCEC's growth. The results show $\mathrm{Z}$ increased the proliferation of both PCHNBECs and PCHBCECs in a dose-dependent manner (Figure 1). PCHBCECs are more sensitive in response to $Z$ treatment than PCHNBECs (Figure 1).

Figure 1. Effects of zeranol on the proliferation of PCHNBECs and PCHBCECs. PCHNBECs and PCHBCECs $\left(5 \times 10^{3}\right.$ cells/well) were treated with $0.1 \%$ DMSO (as a vehicle control), 7.5, 15 and $30 \mathrm{nM}$ zernaol in 96-well plates for $24 \mathrm{~h}$. Non-radioactive cell proliferation assay was performed after $24 \mathrm{~h}$ treatment. Each bar represents the mean $\pm \mathrm{SD}$ of 4 replicate wells. The asterisks show statistically significant differences between $\mathrm{Z}$ treatment groups and the control groups $(p<0.05)$. The figure illustrates that PCHBCECs are more sensitive to $\mathrm{Z}$ treatment than PCHNBECs.

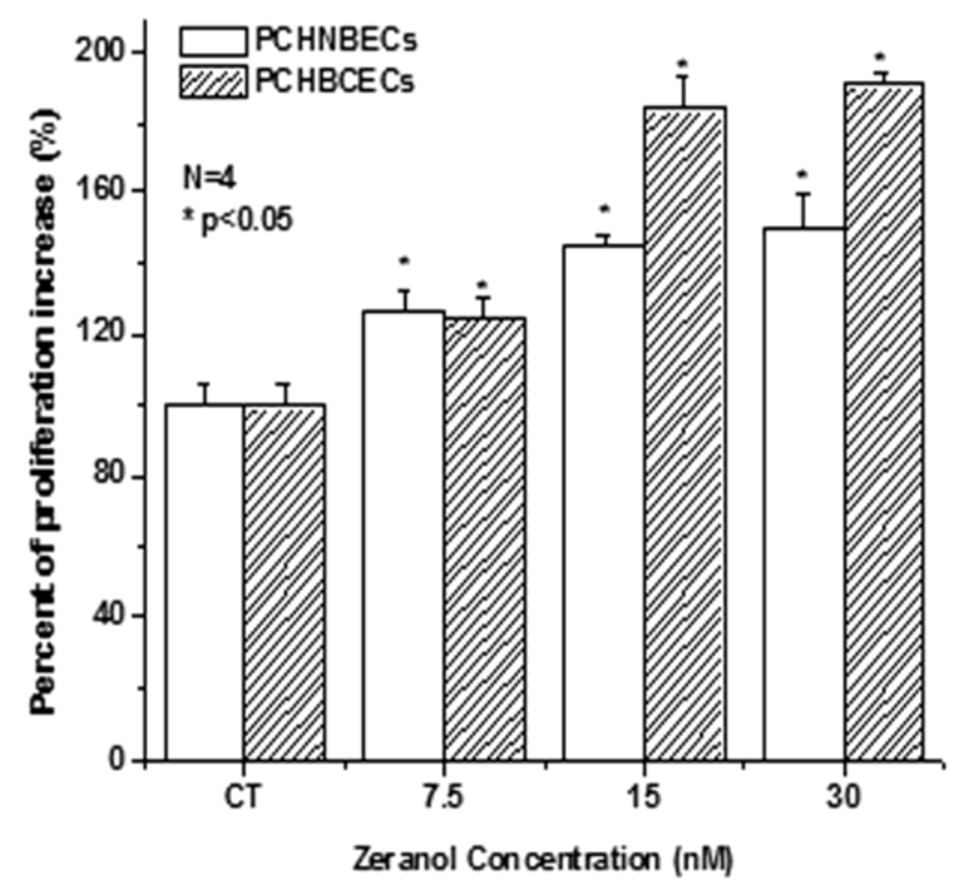

2.2. Regulatory Effects of $Z$ on $p 53$ mRNA and Protein Expression in PCHNBECs and PCHBCECs

In order to explore the possible mechanisms involved in $\mathrm{Z}$ stimulation of PCHNBECs and PCHBCECs proliferation, we examined the expression of the p53 gene at the mRNA and proteins level. p53 is involved in many important physiological processes such as cell cycle arrest, gene transcription, DNA repair, and apoptosis. Our result illustrated that $\mathrm{Z}$ treatment significantly suppressed the level of p53 mRNA and protein expression in PCHBCECs in comparison to the levels in the control group (Figures 2 and 4). However, $\mathrm{Z}$ did not show significant reduction of p53 mRNA and protein expression in PCHNBECs when compared to the control (Figure 2). 
Figure 2. Comparison of effect of $\mathrm{Z}$ on the expression of p53 mRNA in PCHNBECs and PCHBCECs. PCHNBECs and PCHBCECs $\left(1 \times 10^{5}\right.$ cells/well $)$ were seeded in 6-well plates and treated with $0.1 \%$ DMSO, 7.5, 15, and $30 \mathrm{nM} \mathrm{Z}$. After $24 \mathrm{~h}$ treatment, total RNA was isolated from each treatment group and RNA concentrations were measured. Then, cDNA was synthesized and real time PCR was performed to amplify p53 and 36B4 genes. The mRNA ratios of p53 to 36B4 were calculated using the $\Delta \Delta \mathrm{Ct}$ method. Each bar represents mean $\pm \mathrm{SE}$ of three independent experiment. The asterisks show statistically significant differences between $\mathrm{Z}$ treatment groups and the control groups $(p<0.05)$. It shows that $Z$ decreases the expression level of p53 mRNA in PCHBCECs but not in PCHNBECs.

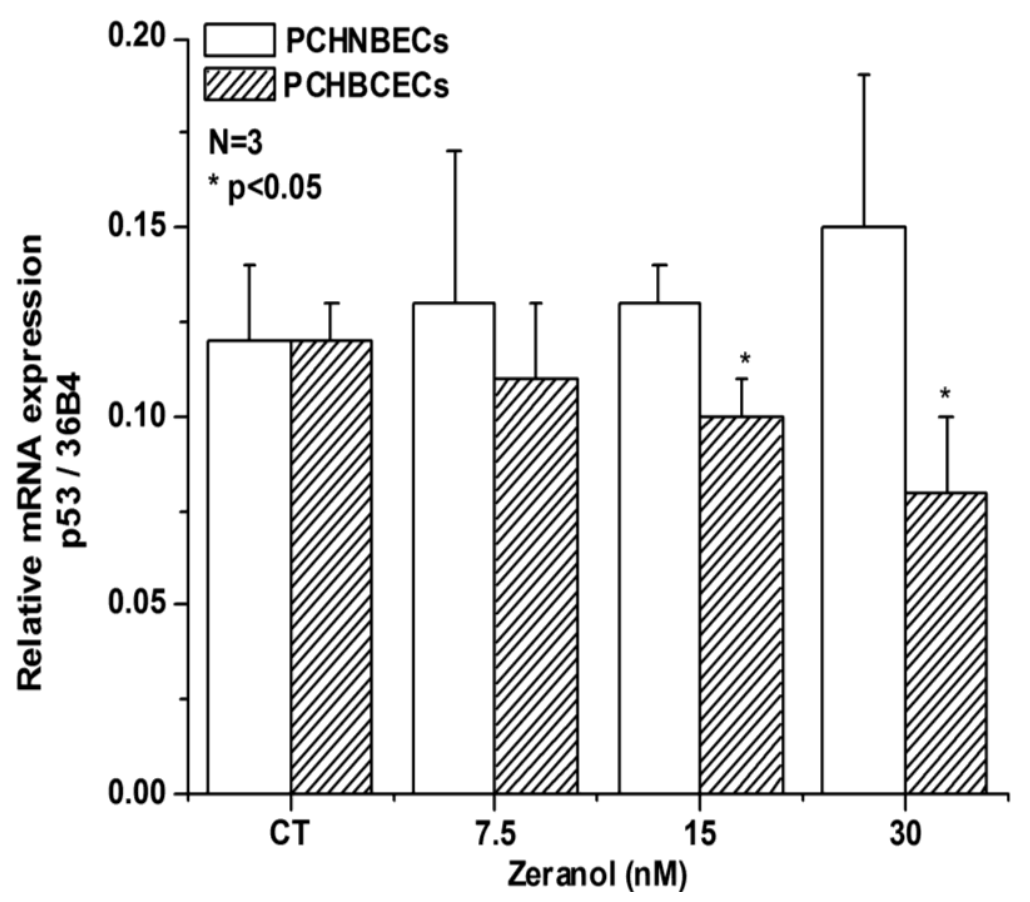

\subsection{Z Regulates the Expression of DNMT1 $m R N A$ and Protein in PCHNBECs and PCHBCECs}

DNMT1 plays an important role in silencing tumor suppressor genes, such as BRCA1, p16, and p21 in breast cancer development. It was reported that DNMT1 is over-expressed in breast cancer [29,30]. To explore the possible mechanisms of $\mathrm{Z}$ regulating p53 gene expression, we investigated the effects of $\mathrm{Z}$ on DNMT1 mRNA and protein expression in PCHNBECs and PCHBCECs after $24 \mathrm{~h}$ treatment. The results are shown in Figures 3 and 4. It is illustrated that $Z$ treatment significantly increased the expression of DNMT1 mRNA and protein levels in PCHBCECs in a dose-dependent manner when compared to the control. However, Z did not significantly increase the expression of DNMT1 mRNA and protein in PCHNBECs when compared to the control. Our results suggest that $\mathrm{Z}$ regulate the expression of p53 in PCHBCECs, maybe through its epigenetic modification. 
Figure 3. Effects of $Z$ on regulation of the expression of DNMT1 mRNA in PCHBCECs and PCHNBECs. The expression levels of DNMT1 mRNA were evaluated in PCHBCECs and PCHNBECs after treatment with vehicle control or 7.5-30 nM Z using real time PCR analysis. 36B4 was used as an internal control. The mRNA ratios of DNMT1 to 36B4 were calculated using the $\Delta \Delta \mathrm{Ct}$ method. The asterisks show statistically significant differences between $\mathrm{Z}$ treatment groups and the control groups $(p<0.05)$.

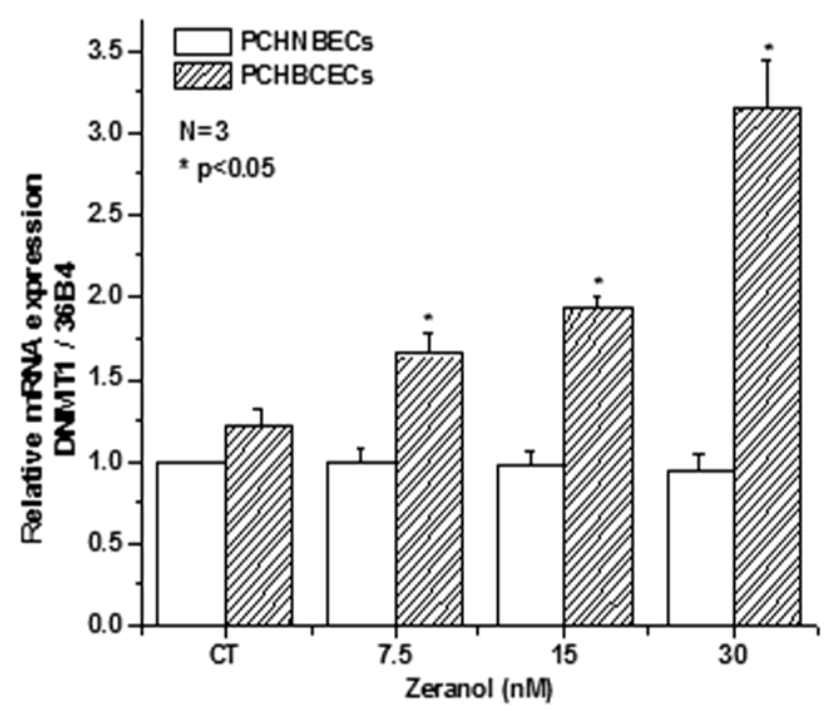

Figure 4. Zeranol regulates the expression of p53 and DNMT1 proteins in PCHNBECs and PCHBCECs. PCHNBECs and PCHBCECs were seeded in $10 \mathrm{~cm}$ culture dishes at a density of $1 \times 10^{6}$ cells/dish and then treated with $7.5,15,30 \mathrm{nM} \mathrm{Z}$ or $0.1 \%$ DMSO as a vehicle control for $24 \mathrm{~h}$. Proteins were extracted from each treatment group and Western blot analysis was conducted. $\beta$-actin was used to confirm equal loading of total proteins during SDS-PAGE.

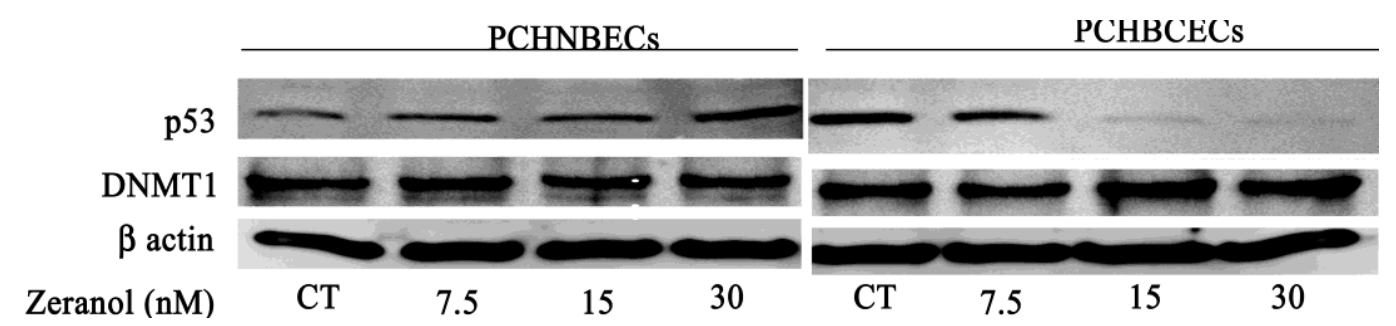

\subsection{Discussion}

Breast cancer development occurs in multiple stages, which are triggered by the evolution of altered gene function. Many of the gene changes that disrupt their coding regions are involved in initiation, promotion and progression [31]. P53 is a tumor suppressor gene which plays a crucial role in regulating cell growth following exposure to various stress stimuli. It induces growth arrest or programmed cell death (apoptosis) and it also plays an important role in the control of cell cycle checkpoints. Research found that p53 is the most frequently mutated gene in human cancers. An estimated 15-60\% of breast cancers contain p53 mutations [32] and loss of p53 occurs in approximately $80 \%$ of colorectal tumors [33]. Consequently, its function has been extensively studied. It was reported that tumor cells with mutant p53 protein might be associated with poor prognosis [32]. 
The tumor suppressor p53 can regulate both cell proliferation and apoptosis. An imbalance between cell proliferation and apoptosis results in a rapid increase in cell number, the most prominent characteristic of tumors. Normal breast epithelial cells induce p53-dependent apoptosis and p53-independent cell cycle arrest of breast cancer cells [34]. In addition, p53 was also expected to play an important role in cancer treatment with its mutation predicting a substantially worsened prognosis [33]. Several retrospective studies have suggested p53 gene mutation as an adverse prognostic indicator in breast cancer patients; it can predict early recurrence, sensitivity to chemotherapy, and death in breast cancer patients [35].

Recently, it is becoming understood that epigenetic events, or heritable changes in gene expression capacity without DNA sequence alterations, are also central to tumor progression. Understanding the differential roles of regional hypermethylation and global hypomethylation in breast cancer will facilitate novel therapeutic approaches to breast cancer therapy. It was found that hypomethylation of the global genome can lead to genomic instability that is exemplified by misalignments, DNA breakage, deletions and duplications during DNA replication [36].

DNA methylation is one of the major epigenetic modifications in cancer development which has a long-standing relationship with gene inactivity and has been implicated as an important factor in gene silencing [37,38]. In humans and most mammals, DNA methylation is the only known natural modification of DNA and only affects cytosines at the 5' position when it is followed by a guanosine, known as $\mathrm{CpG}$ dinucleotides. Depending on the cell types and tissue, 3-4\% of all cytosine residues in vertebrate DNA may be present as 5-methylcytosine and approximately 70 to $80 \%$ of all CpG dinucleotides in human DNA are methylated [39]. However, this methylation occurs primarily in areas where $\mathrm{CpG}$ density is low, or at repeat DNA sites. Most $\mathrm{CpG}$ islands, especially those located in promoter region of a specific gene, are completely unmethylated. Interestingly, fully methylated CpG islands are found only in the promoters of silenced alleles for selected imprinted autosomal genes and multiple silenced genes on the inactivated X-chromosomes of females [40]. It is well established that almost half of the tumor suppressor genes that cause familial cancers through germline mutations can be inactivated in association with promoter hypermethylation in sporadic cancers [41]. Huang and colleagues, using a novel DNA array based technique called differential methylation hybridization, performed a genome wide screen for hypermethylated $\mathrm{CpG}$ islands in a panel of breast cancer cell lines. They found that approximately $10 \%$ of $\mathrm{CpG}$ islands exhibited methylation in normal breast epithelial cells. In contrast, breast cancer cell lines show methylation at a considerably larger fraction of CpG islands (15-25\%) [42]. In clinical research, it was reported that DNA methylation in serum of breast cancer patients may be considered as an independent prognostic marker [43]. Methylation-dependent gene silencing is now thought to be mediated through local changes in chromatin conformation that limit promoter accessibility [44].

DNA methyltransferases (DNMTs) are critical enzymes that regulate DNA methylation. DNMT1 is the most important one; the $N$-terminus of DNMT1 contains regions responsible for targeting the enzyme to replication foci [45], as well as for discriminating between unmethylated and hemi-methylated DNA [46]. Overexpression of all the DNMTs at the mRNA level has been shown for several cancers [47-49]. Conversely, a mouse model for colon cancer demonstrated that reducing DNMT1 expression and activity via hemizygous knockout of the gene and treatment with a DNMT1 inhibitor greatly reduced the number of intestinal adenomas [50]. Similarly, Macleod and Szyf found 
that transfection of a murine adrenocortical tumor cell line with DNMT1 antisense expression vectors resulted in general DNA hypomethylation, growth inhibition in vitro, and decreased tumorigenicity in vivo [51]. Our laboratory recently reported PTP $\gamma$ expression was reduced in breast cancer cell lines, SK-Br-3 and MCF-7 cells, and it can be re-activated with the treatment of deoxy-5-azacytidine, a well-known DNMT1 inhibitor [52]. These results suggest that DNMT1 can be thought of as a new target for novel drug development.

Our data indicated that $24 \mathrm{~h} \mathrm{Z}$ treatment stimulated both PCHNBEC's and PCHBCEC's proliferation in a dose-dependent manner, and PCHBCECs were more sensitive to $Z$ than PCHNBECs. $\mathrm{Z}$ increased the DNMT1 expression in PCHBCECs and decreased the p53 expression at both the mRNA and protein levels; however, no such effect was found in PCHNBECs, suggesting $Z$ might be more harmful to cancer patients than normal and $\mathrm{Z}$ might have adverse health problem when cancer patients intake beef products produced by Z-implanted beef cattle containing $\mathrm{Z}$ or its metabolites. One of the mechanisms is due to the increase of DNMT1 and decrease of p53 expression. In addition, all our experimental data was collected from matched human breast tissues, which can provide better data for analyzing the difference between PCHNBECs and PCHBCECs with the same treatment of different concentrations of $\mathrm{Z}$ to decrease the possible influence of age, sex, medication, life style, etc.

In summary, our data show PCHBCECs may be more sensitive to exposure to $Z$. The stimulatory effects of $\mathrm{Z}$ on PCHBCECs might be possible through down-regulation of the expression of the p53 gene and up-regulation of DNMT1 mRNA and protein. This result suggests that suppressed expression of the p53 gene in PCHBCECs might be mediated through its epigenetic modification. Further investigation into this critical issue is in progress in our laboratory.

\section{Experimental Section}

\subsection{Isolation of Primary Cultured Human Normal Breast Epithelial Cells (PCHNBECs) and Cancer Epithelial Cells (PCHBCECs)}

Human normal and cancerous breast tissues from the same patient were obtained through the Tissue Procurement Program of The Ohio State University Comprehensive Cancer Center Hospital in Columbus, OH, USA. After tissues were transferred in our laboratory, they were minced and then digested using digestion buffer which consisted of phenol red-free high calcium Dulbecco's modified Eagle's medium and Ham's F12 medium (1:1) (DMEM/F12) (1.05 mM CaCl 2$)$ with 2\% Bovine Serum Albumin (BSA) (Invitrogen, Carlsbad, CA, USA) containing $10 \mathrm{ng} / \mathrm{mL}$ Cholera toxin (Sigma, St. Louis, MO, USA), $6300 \mathrm{U} / \mathrm{mL}$ Collagenase (Invitrogen), and $100 \mathrm{U} / \mathrm{mL}$ Hyalurinidase (Calbiochem, Gibbstown, NJ, USA). After the mixture was incubated in a humidified incubator (5\% $\mathrm{CO}_{2}, 95 \%$ air, $37{ }^{\circ} \mathrm{C}$ ) overnight, the solution was transferred to a $50 \mathrm{~mL}$ tube and centrifuged at $1200 \mathrm{rpm}$ for $5 \mathrm{~min}$. The upper layer containing pre-adipocytes and middle layer containing stromal cells were transferred to another $15 \mathrm{~mL}$ tube separately while the pellet containing epithelial cells remained in the tube. All the pellets were washed by DMEM/F12 medium with antibiotic-antimycotic (100 U/mL penicillin $\mathrm{G}$ sodium, $100 \mu \mathrm{g} / \mathrm{mL}$ streptomycin sulfate and $0.25 \mu \mathrm{g} / \mathrm{mL}$ amphotericin B) (Invitrogen) and centrifuged again. This wash procedure was repeated three times. The final pellet in the tube contains PCHBCECs or PCHNBECs. The pellet was then resuspended in $10 \mathrm{~mL}$ low calcium (0.04 $\mathrm{mM} \mathrm{CaCl}_{2}$ ) DMEM/F12 medium supplemented with $10 \%$ of low calcium FBS (Atlanta 
Biologicals, Norcross, GA, USA) and then transferred into a T75 flask for culturing. The method and the specific cultural medium ensure the purity of PCHBCECs or PCHNBECs isolated from normal or cancerous breast tissues. Our lab members have determined the purity of the isolated primary cultured human normal and cancerous breast epithelial cells or stromal cells by using immunocytochemistry [53].

\subsection{PCHBCECs and PCHNBECs Culture}

The isolated PCHNBECs and PCHBCECs were cultured in $75 \mathrm{~cm}^{2}$ culture flasks in a humidified incubator $\left(5 \% \mathrm{CO}_{2}, 95 \%\right.$ air, $\left.37{ }^{\circ} \mathrm{C}\right)$ with $10 \mathrm{~mL}$ low calcium $\left(0.04 \mathrm{mM} \mathrm{CaCl}_{2}\right)$ DMEM/F12 mixture (Atlanta Biologicals, Norcross, GA, USA) supplemented with 10\% of Chelex-100 (Bio-Rad Laboratories, Richmond, CA, USA) treated FBS (Invitrogen). The low calcium DMEM/F12 medium was changed every two days [10]. This was done to ensure the purity of PCHNBECs and PCHBCECs. When the cells grew to $85-90 \%$ confluence, cells were washed with $10 \mathrm{~mL}$ of calcium- and magnesium-free Phosphate Buffered Saline (PBS, pH 7.3), and then trypsinized with $3 \mathrm{~mL}$ of $0.25 \%$ trypsin-5.3 mM EDTA (Invitrogen) for 5-8 min at $37{ }^{\circ} \mathrm{C}$. The trypsinization was stopped by addition of $10 \mathrm{~mL}$ of DMEM/F12 medium with $10 \%$ FBS. After centrifugation, the dissociated cells were resuspended in low calcium DMEM/F12 medium with 10\% low calcium FBS and sub-cultured into $75 \mathrm{~cm}^{2}$ culture flasks at a ratio of 1 flask to 3 flasks. All experiments were conducted on primary cultured human normal breast epithelial cells not generated beyond the fourth passage.

\subsection{Cell Proliferation Assay (MTT Assay)}

A total volume of $100 \mu \mathrm{L}$ medium containing 5000 PCHNBECs or PCHBCECs/well was seeded in 96-well plates in low calcium DMEM/F12 medium and incubated at $37{ }^{\circ} \mathrm{C}$ for $24 \mathrm{~h}$. The following day, medium was replaced by $100 \mu \mathrm{L}$ low calcium DMEM/F12 supplemented with $0.2 \%$ BSA and incubated at $37{ }^{\circ} \mathrm{C}$ for another $24 \mathrm{~h}$. After, the treatment of $7.5,15,30 \mathrm{nM} \mathrm{Z}$ was given for $24 \mathrm{~h}(0.1 \%$ DMSO to control group), the proliferation of PCHNBECs and PCHBCECs was measured by adding $20 \mu \mathrm{L}$ of a fresh mixture of 3-(4,5-dimethylthiazol-2-yl)-5-(3-carboxymethoxy-phenyl)-2-(4sulfophenyl)-2H-tetrazolium (MTS) and phenazine methosulfate (PMS) (20:1) solution (Promega, Madison, WI, USA) to each well. After incubation at $37{ }^{\circ} \mathrm{C}$ for $1-3 \mathrm{~h}$, optical density were measured by kinetic microplate reader (Molecular Devices Cooperation, Menio Park, CA, USA) at $490 \mathrm{~nm}$ wavelength and cell growth was compared.

\subsection{Cell Treatment, RNA Isolation and cDNA Synthesis}

A total of $1 \times 10^{5}$ viable PCHNBECs and PCHBCECs/well were seeded in 6-well plates in $5 \mathrm{~mL}$ low calcium DMEM/F12 medium supplemented with 10\% of Chelex-100 (Bio-Rad Laboratories, Hercules, CA, USA) treated FBS (Invitrogen). After $24 \mathrm{~h}$, medium was replaced with low calcium DMEM/F12 supplemented with 10\% dextran coated charcoal (DCC) stripped FBS, and the cells were cultured overnight. After PCHNBECs and PCHBCECs were treated with 0.1\% DMSO, 7.5, 15 and $30 \mathrm{nM} \mathrm{Z}$ for $24 \mathrm{~h}$, total RNA was isolated in $1 \mathrm{~mL}$ TRIZOL Reagent (Invitrogen) according to the manufacturer's instructions. RNA concentration was measured by DU-70 spectrophotometer (Beckman Instruments Inc. Fullerton, CA, USA). RNA $(1 \mu \mathrm{g})$ from cultured cells was reverse 
transcribed with $200 \mathrm{UM}-\mathrm{MLV}$ Reverse Transcriptase (Invitrogen) at $37{ }^{\circ} \mathrm{C}$ for $50 \mathrm{~min}$ then $70{ }^{\circ} \mathrm{C}$ for $15 \mathrm{~min}$ in the presence of $1 \mu \mathrm{L} 10 \mathrm{mM}$ dNTP $(10 \mathrm{mM}$ each dATP, dGTP, dCTP, and dTTP at neutral PH) (Invitrogen), $1 \mu \mathrm{L} 50 \mu \mathrm{M}$ Random hexamer (Amersham, Piscataway, NJ, USA), $10 \mu \mathrm{L} 5 \times$ First Strand buffer, $5 \mu \mathrm{L} 0.1 \mathrm{M}$ DTT and $1 \mu \mathrm{L}$ RNase Inhibitor (Invitrogen) in a total volume of $50 \mu \mathrm{L}$ in a gradient mastercycle (Eppendorf ${ }^{\circledR}$, Westbury, NY, USA).

\subsection{Real Time PCR}

After cDNA was synthesized, real-time PCR was conducted to amplify p53, DNMT1 and 36B4 genes. The PCR reactions for p53, DNMT1 and 36B4 were performed using the SYBR Green I detection chemistry system and detected with the Stratagene M3005XP system (Agilent Technologies, Cedar Creek, TX, USA). For each PCR run, a mixture contained $10 \mu \mathrm{L} 2 \times \mathrm{SYBR}^{\circledR}$ Green PCR master mix (Applied Biosystems, Foster City, CA, USA), $2 \mu \mathrm{L}$ newly synthesized cDNA, $5 \mu \mathrm{L}$ primer mixer and $3 \mu \mathrm{L}$ PCR grade water in a total volume of $20 \mu \mathrm{L}$. The thermal cycling condition comprised an initial step at $50{ }^{\circ} \mathrm{C}$ for $2 \mathrm{~min}, 95{ }^{\circ} \mathrm{C}$ for $10 \mathrm{~min}$, and 45 cycles at $95{ }^{\circ} \mathrm{C}$ for $15 \mathrm{~s}$ and annealing and elongation at $55{ }^{\circ} \mathrm{C}$ for $1 \mathrm{~min}$. Dissociation curves were also conducted after amplification to ensure the reaction specificity. The primer sequences for p53 were 5'-GCT CCT GTG CTG CGA AGT GG-3' (sense) and 5'-TGG AGG CGT CGG TGT AGA TG-3' (antisense, product size 372 bp). The primer sequences for DNMT1 were 5'-CAT TTT ATC CCC ATT GAG AAG TA-3' (sense) and 5'-CTG AAA ATT AAG TCC TTG TGC CCA G-3' (antisense, product size $273 \mathrm{bp}$ ). The primer sequences for 36B4, an internal control were 5'-AAA CTG CTG CCT CAT ATC CG-3' (sense) and 5'-TTT CAG CAA GTG GGA AGG TG-3' (antisense, product size $563 \mathrm{bp}$ ). The results were presented as the ratio of $\mathrm{p} 53$ or DNMT1 to $36 \mathrm{~B} 4$.

\subsection{Western Blotting Assay}

PCHBCECs and PCHNBECs were plated in a $10 \mathrm{~cm}$ culture dish with a density of $1 \times 10^{6}$ viable cells/dish within $10 \mathrm{~mL}$ low calcium DMEM/F12 supplement with 10\% FBS and cultured overnight. The media was replaced with low calcium DMEM/F12 supplemented with 5\% DCC treated FBS and was cultured for another $24 \mathrm{~h}$. PCHBCECs and PCHNBECs treatment were the same as previously described. After $24 \mathrm{~h}$ treatment, proteins were extracted from each treatment group using M-PER ${ }^{\circledR}$ mammalian protein extraction reagent (Pierce, Rockford, IL, USA) according to the manufacturer's instructions. Protein concentrations were measured using a Micro $\mathrm{BCA}^{\mathrm{TM}}$ protein assay reagent kit (Pierce, Rockford, IL, USA) following the manufacturer's protocol. Proteins (50 $\mu \mathrm{g}$ ) from each treatment group were separated by $4-15 \%$ Tris- $\mathrm{HCl}$ gel electrophoresis and then transferred to a Polyvinylidine Fluoride (PVDF) membrane (Bio-Rad Laboratory, Hercules, CA, USA). The membrane was first blocked in Phosphate Buffered Saline $-0.1 \%$ Tween 20 (PBST) containing $10 \%$ fat free dry milk for $1 \mathrm{~h}$ and then incubated with DNMT1 goat polyclonal antibody (dilution 1:500, sc-10219, Santa Cruz Biotechnology, Inc. Santa Cruz, CA, USA), p53 antibody (1:1000 dilution, Cell Signaling Technology ${ }^{\circledR}$ Danvers, MA, USA) and $\beta$-actin antibody (1:2000 dilution, Santa Cruz Biotechnology, Inc.) for $1 \mathrm{~h}$. The membrane was rinsed in PBST three times, each time for $5 \mathrm{~min}$. In the following step, the membrane was incubated with second antibody (donkey anti-goat IgG-horseradish peroxidase HRP for DNMT1 and $\beta$ actin; ECLTM anti-rabbit IgG-HRP for detecting 
p53) for $1 \mathrm{~h}$. After washing the membrane in PBST three times, p53, DNMT1, and $\beta$-actin protein were visualized with a chemiluminescent detection system (ECL, Amersham Pharmacia Biotech, Buckinghamshire, UK). Pictures were taken using a FujiFilm LAS-300 imaging system (FUJIFILM Medical Systems USA, Inc.). The protein ratios of $\mathrm{p} 53$ to $\beta$-actin and DNMT1 to $\beta$-actin were calculated by measuring the density of the specific band using Multi-Gauge software (v3.0).

\subsection{Statistical Analysis}

The results for the cell proliferation assay are presented compared to the control group as mean \pm standard deviation (SD) for 4 replicate culture wells. The results for the mRNA expression are presented compared to the control group as mean \pm standard deviation (SD) for 3 replicates. Analyses were performed using Minitab 15 software (Minitab Inc. PA, USA). Statistical differences were determined by using two sample $t$-test or ANOVA analysis for independent samples. $P$-values of less than 0.05 were considered statistically significant differences.

\section{Conclusions}

Our experimental results demonstrated that the growth promoter $\mathrm{Z}$ stimulates the proliferation of PCHBCECs. The stimulatory effects of $Z$ on the cells may be mediated by down-regulating the tumor suppressor gene p53 at the mRNA and protein levels. Further investigation illustrated that the DNA methylatransferase $1 \mathrm{mRNA}$ and protein levels were up-regulated by the treatment of $\mathrm{Z}$ in PCHBCECs as compared to PCHNBECs, which suggests a role of $Z$ in epigenetic modification involved in the regulation of p53 gene expression in PCHBCECs. Our experimental results imply the potential adverse health effect of $\mathrm{Z}$ in breast cancer development. Further study is under process in our laboratory

\section{Acknowledgements}

The authors thank Rikihisa's laboratory for providing photo-documentation equipment. This work was supported by the RO1 ES 015212 (National Institutes of Health, USA)

\section{References}

1. Jemal, A.; Siegel, R.; Xu, J.; Ward, E. Cancer Statistics, 2010. CA Cancer J. Clin. 2010, 60, 277-300.

2. Chetrite, G.S.; Cortes-Prieto, J.; Philippe, J.C.; Wright, F.; Pasqualini, J.R. Comparison of estrogen concentrations, estrone sulfatase and aromatase activities in normal, and in cancerous, human breast tissues. J. Steroid Biochem. Mol. Biol. 2000, 72, 23-27.

3. Haynes, B.P.; Straume, A.H.; Geisler, J.; A'Hern, R.; Helle, H.; Smith, I.E.; Lonning, P.E.; Dowsett, M. Intratumoral estrogen disposition in breast cancer. Clin. Cancer Res. 2010, 16, 1790-1801.

4. Minervini, F.; Giannoccaro, A.; Cavallini, A.; Visconti, A. Investigations on cellular proliferation induced by zearalenone and its derivatives in relation to the estrogenic parameters. Toxicol. Lett. 2005, 159, 272-283.

5. Massart, F.; Meucci, V.; Saggese, G.; Soldani, G. High growth rate of girls with precocious puberty exposed to estrogenic mycotoxins. J. Pediatrics 2008, 152, 690-695. 
6. Takemura, H.; Shim, J.Y.; Sayama, K.; Tsubura, A.; Zhu, B.T.; Shimoi, K. Characterization of the estrogenic activities of zearalenone and zeranol in vivo and in vitro. J. Steroid Biochem. Mol. Biol. 2007, 103, 170-177.

7. Liu, S.; Sugimoto, Y.; Kulp, S.K.; Jiang, J.; Chang, H.L.; Park, K.Y.; Kashida, Y.; Lin, Y.C. Estrogenic down-regulation of protein tyrosine phosphatase gamma (PTP gamma) in human breast is associated with estrogen receptor alpha. Anticancer Res. 2002, 22, 3917-3923.

8. Coe, J.E.; Ishak, K.G.; Ward, J.M.; Ross, M.J. Tamoxifen prevents induction of hepatic neoplasia by zeranol, an estrogenic food contaminant. Proc. Natl. Acad. Sci. USA 1992, 89, 1085-1089.

9. Yuri, T.; Tsukamoto, R.; Miki, K.; Uehara, N.; Matsuoka, Y.; Tsubura, A. Biphasic effects of zeranol on the growth of estrogen receptor-positive human breast carcinoma cells. Oncol. Rep. 2006, 16, $1307-1312$.

10. Liu, S.; Lin, Y.C. Transformation of MCF-10A human breast epithelial cells by zeranol and estradiol-17beta. Breast J. 2004, 10, 514-521.

11. Ye, W.; Xu, P.; Threlfall, W.R.; Jen, R.; Li, H.; Lin, S.H.; Kuo, C.T.; Lin, Y.C. Zeranol enhances the proliferation of pre-adipocytes in beef heifers. Anticancer Res. 2009, 29, 5045-5052.

12. Ye, W.; Xu, P.; Zhong, S.; Threlfall, W.R.; Frasure, C.; Feng, E.; Li, H.; Lin, S.H.; Liu, J.Y.; Lin, Y.C. Serum harvested from heifers one month post-zeranol implantation stimulates MCF-7 breast cancer growth. Exp. Ther. Med. 2010, 1, 963-968.

13. Ye, W.; Xu, P.; Zhong, S.; Jen, R.; Threlfall, W.R.; Frasure, C.V.; Feng, E.; Li, H.; Lin, S.H.; Liu, J.Y.; Lin, Y.C. In vitro transformation of MCF-10A cells by sera harvested from heifers two months post-Zeranol implantation. Int. J. Oncol. 2011, 38, 985-992.

14. Xu, P.; Ye, W.; Jen, R.; Lin, S.H.; Kuo, C.T.; Lin, Y.C. Mitogenic activity of zeranol in human breast cancer cells is enhanced by leptin and suppressed by gossypol. Anticancer Res. 2009, 29, 4621-4628.

15. Swan, S.H.; Liu, F.; Overstreet, J.W.; Brazil, C.; Skakkebaek, N.E. Semen quality of fertile US males in relation to their mothers' beef consumption during pregnancy. Hum. Reprod. 2007, 22, 1497-1502.

16. Linos, E.; Willett, W.C.; Cho, E.; Colditz, G.; Frazier, L.A. Red meat consumption during adolescence among premenopausal women and risk of breast cancer. Cancer Epidemiol. Biomarkers Prev. 2008, 17, 2146-2151.

17. Aw, T.C.; Smith, A.B.; Stephenson, R.L.; Glueck, C.J. Occupational exposure to zeranol, an animal growth promoter. Br. J. Ind. Med. 1989, 46, 341-346.

18. Vogelstein, B.; Lane, D.; Levine, A.J. Surfing the p53 network. Nature 2000, 408, 307-310.

19. Golubovskaya, V.M.; Conway-Dorsey, K.; Edmiston, S.N.; Tse, C.K.; Lark, A.A.; Livasy, C.A.; Moore, D.; Millikan, R.C.; Cance, W.G. FAK overexpression and p53 mutations are highly correlated in human breast cancer. Int. J. Cancer 2009, 125, 1735-1738.

20. Dinu, I.; Potter, J.D.; Mueller, T.; Liu, Q.; Adewale, A.J.; Jhangri, G.S.; Einecke, G.; Famulski, K.S.; Halloran, P.; Yasui, Y. Gene-set analysis and reduction. Briefings Bioinf. 2009, 10, 24-34.

21. Hassan, N.M.; Tada, M.; Hamada, J.; Kashiwazaki, H.; Kameyama, T.; Akhter, R.;Yamazaki, Y.; Yano, M.; Inoue, N.; Moriuchi, T. Presence of dominant negative mutation of TP53 is a risk of early recurrence in oral cancer. Cancer Lett. 2008, 270, 108-119. 
22. Baker, L.; Quinlan, P.R.; Patten, N.; Ashfield, A.; Birse-Stewart-Bell, L.J.; McCowan, C.; Bourdon, J.C.; Purdie, C.A.; Jordan, L.B.; Dewar, J.A.; Wu, L.; Thompson, A.M. p53 mutation, deprivation and poor prognosis in primary breast cancer. Br. J. Cancer 2010, 102, 719-726.

23. Lai, H.; Lin, L.; Nadji, M.; Lai, S.; Trapido, E.; Meng, L. Mutations in the p53 tumor suppressor gene and early onset breast cancer. Cancer Biol. Ther. 2002, 1, 31-36.

24. Xu, X.; Wagner, K.U.; Larson, D.; Weaver, Z.; Li, C.; Ried, T.; Hennighausen, L.; Wynshaw-Boris, A.; Deng, C.X. Conditional mutation of Brca1 in mammary epithelial cells results in blunted ductal morphogenesis and tumour formation. Nat. Genet. 1999, 22, 37-43.

25. Ting, A.H.; Jair, K.W.; Schuebel, K.E.; Baylin, S.B. Differential requirement for DNA methyltransferase 1 in maintaining human cancer cell gene promoter hypermethylation. Cancer Res. 2006, 66, 729-735.

26. Xu, X.L.; Yu, J.; Zhang, H.Y.; Sun, M.H.; Gu, J.; Du, X.; Shi, D.R.; Wang, P.; Yang, Z.H.; Zhu, J.D. Methylation profile of the promoter $\mathrm{CpG}$ islands of 31 genes that may contribute to colorectal carcinogenesis. World J. Gastroenterol. 2004, 10, 3441-3454.

27. Datta, J.; Ghoshal, K.; Denny, W.A.; Gamage, S.A.; Brooke, D.G.; Phiasivongsa, P.; Redkar, S.; Jacob, S.T. A new class of quinoline-based DNA hypomethylating agents reactivates tumor suppressor genes by blocking DNA methyltransferase 1 activity and inducing its degradation. Cancer Res. 2009, 69, 4277-4285.

28. Kang, J.H.; Kim, S.J.; Noh, D.Y.; Park, I.A.; Choe, K.J.; Yoo, O.J.; Kang, H.S. Methylation in the p53 promoter is a supplementary route to breast carcinogenesis: correlation between $\mathrm{CpG}$ methylation in the p53 promoter and the mutation of the p53 gene in the progression from ductal carcinoma in situ to invasive ductal carcinoma. Lab. Invest. 2001, 81, 573-579.

29. Girault, I.; Tozlu, S.; Lidereau, R.; Bieche, I. Expression analysis of DNA methyltransferases 1, 3A, and 3B in sporadic breast carcinomas. Clin. Cancer Res. 2003, 9, 4415-4422.

30. Agoston, A.T.; Argani, P.; de Marzo, A.M.; Hicks, J.L.; Nelson, W.G. Retinoblastoma pathway dysregulation causes DNA methyltransferase 1 overexpression in cancer via MAD2-mediated inhibition of the anaphase-promoting complex. Am. J. Pathol. 2007, 170, 1585-1593.

31. Weiss, R.A. Multistage carcinogenesis. Br. J. Cancer 2004, 91, 1981-1982.

32. Hartmann, A.; Blaszyk, H.; Kovach, J.S.; Sommer, S.S. The molecular epidemiology of p53 gene mutations in human breast cancer. Trends Genet. 1997, 13, 27-33.

33. McGill, G.; Fisher, D.E. p53 and cancer therapy: a double-edged sword. J. Clin. Invest. 1999, 104, 223-225.

34. Toillon, R.A.; Chopin, V.; Jouy, N.; Fauquette, W.; Boilly, B.; Le Bourhis, X. Normal breast epithelial cells induce p53-dependent apoptosis and p53-independent cell cycle arrest of breast cancer cells. Breast Cancer Res. Treat. 2002, 71, 269-280.

35. Blaszyk, H.; Hartmann, A.; Cunningham, J.M.; Schaid, D.; Wold, L.E.; Kovach, J.S.; Sommer, S.S. A prospective trial of midwest breast cancer patients: A p53 gene mutation is the most important predictor of adverse outcome. Int. J. Cancer 2000, 89, 32-38.

36. Baylin, S.B.; Herman, J.G.; Graff, J.R.; Vertino, P.M.; Issa, J.P. Alterations in DNA methylation: A fundamental aspect of neoplasia. Adv. Cancer Res. 1998, 72, 141-196. 
37. Ai, L.; Tao, Q.; Zhong, S.; Fields, C.R.; Kim, W.J.; Lee, M.W.; Cui, Y.; Brown, K.D.; Robertson, K.D. Inactivation of Wnt inhibitory factor-1 (WIF1) expression by epigenetic silencing is a common event in breast cancer. Carcinogenesis 2006, 27, 1341-1348.

38. Rivenbark, A.G.; Jones, W.D.; Risher, J.D.; Coleman, W.B. DNA methylation-dependent epigenetic regulation of gene expression in MCF-7 breast cancer cells. Epigenetics 2006, 1, 32-44.

39. Razin, A.; Riggs, A.D. DNA methylation and gene function. Science 1980, 210, 604-610.

40. Surani, M.A. Imprinting and the initiation of gene silencing in the germ line. Cell 1998, 93, 309-312.

41. Baylin, S.B.; Herman, J.G. DNA hypermethylation in tumorigenesis: epigenetics joins genetics. Trends Genet. 2000, 16, 168-174.

42. Huang, T.H.; Perry, M.R.; Laux, D.E. Methylation profiling of CpG islands in human breast cancer cells. Hum. Mol. Genet. 1999, 8, 459-470.

43. Muller, H.M.; Widschwendter, A.; Fiegl, H.; Ivarsson, L.; Goebel, G.; Perkmann, E.; Marth, C.; Widschwendter, M. DNA methylation in serum of breast cancer patients: An independent prognostic marker. Cancer Res. 2003, 63, 7641-7645.

44. Razin, A. CpG methylation, chromatin structure and gene silencing-a three-way connection. EMBO J. 1998, 17, 4905-4908.

45. Leonhardt, H.; Page, A.W.; Weier, H.U.; Bestor, T.H. A targeting sequence directs DNA methyltransferase to sites of DNA replication in mammalian nuclei. Cell 1992, 71, 865-873.

46. Bestor, T.H.; Gundersen, G.; Kolsto, A.B.; Prydz, H. CpG islands in mammalian gene promoters are inherently resistant to de novo methylation. Genet. Anal. Tech. Appl. 1992, 9, 48-53.

47. Issa, J.P.; Vertino, P.M.; Wu, J.; Sazawal, S.; Celano, P.; Nelkin, B.D.; Hamilton, S.R.; Baylin, S.B. Increased cytosine DNA-methyltransferase activity during colon cancer progression. J. Natl. Cancer Inst. 1993, 85, 1235-1240.

48. Robertson, K.D.; Uzvolgyi, E.; Liang, G.; Talmadge, C.; Sumegi, J.; Gonzales, F.A.; Jones, P.A. The human DNA methyltransferases (DNMTs) 1, 3a and 3b: coordinate mRNA expression in normal tissues and overexpression in tumors. Nucleic Acids Res. 1999, 27, 2291-2298.

49. Ahluwalia, A.; Hurteau, J.A.; Bigsby, R.M.; Nephew, K.P. DNA methylation in ovarian cancer. II. Expression of DNA methyltransferases in ovarian cancer cell lines and normal ovarian epithelial cells. Gynecol. Oncol. 2001, 82, 299-304.

50. Laird, P.W.; Jackson-Grusby, L.; Fazeli, A.; Dickinson, S.L.; Jung, W.E.; Li, E.; Weinberg, R.A.; Jaenisch, R. Suppression of intestinal neoplasia by DNA hypomethylation. Cell 1995, 81, 197-205.

51. MacLeod, A.R.; Szyf, M. Expression of antsense to DNA methyltransferase mRNA induces DNA demethylation and inhibits tumorigenesis. J. Biol. Chem. 1995, 270, 8037-8043.

52. Shu, S.T.; Sugimoto, Y.; Liu, S.; Chang, H.L.; Ye ,W.; Wang, L.S.; Huang, Y.W.; Yan, P.; Lin, Y.C. Function and regulatory mechanisms of the candidate tumor suppressor receptor protein tyrosine phosphatase gamma (PTPRG) in breast cancer cells. Anticancer Res. 2010, 30, 1937-1946.

53. Liu, S.; Kulp, S.K.; Sugimoto, Y.; Jiang, J.; Chang, H.L.; Lin, Y. Involvement of breast epithelial-stromal interactions in the regulation of protein tyrosine phosphatase- $\gamma$ (PTP $\gamma$ ) mRNA expression by estrogenically active agents. Breast Cancer Res. Treat. 2002, 71, 21-35.

(C) 2011 by the authors; licensee MDPI, Basel, Switzerland. This article is an open access article distributed under the terms and conditions of the Creative Commons Attribution license (http://creativecommons.org/licenses/by/3.0/). 